\title{
End-of-Dinner Food Offering: A Three-Way Contrastive Study
}

\author{
Rong Chen \\ Professor, Xi'an International Studies University, California State University, \\ San Bernardino, California \\ rchen@csusb.edu
}

Chunmei $\mathrm{Hu}$

Associate Professor, School of English Studies, Xi'an International Studies University, Xi'an, China

huchunmei@xisu.edu.cn

\begin{abstract}
This paper presents a three-way contrastive study of the structure of the end-ofdinner food offering event - hosts asking guests to eat more food when the latter have indicated that they have finished eating - across three population groups: Chinese residents of the City of Xi'an as of 1995 (as reported in Chen, 1996), American residents of Southern California as of 2019, and Chinese residents of Xi'an as of 2019. It is found that, in 2019, Americans living in Southern California only infrequently offer their guests more food at the end of a dinner, while the Chinese residents of Xi'an (the Xi'an Chinese) offer their guests food much less often than in 1995, although still more frequently than their American counterparts. The difference observed between the Chinese and American groups is attributed to the different notions of politeness that are held in the two cultures: the Xi'an Chinese still maintain elements of hospitality and warmth as key notions of politeness, in a similar way to Libyan Arabic speakers, as discovered by Grainger, Mansor and Mills (2015), while the offering behaviour of Southern Californians is motivated by the respect they hold for another person's freedom of action. The noticeable change in the way food is offered at the end of a Chinese dinner between 1995 and 2019 - which can be seen to be a process of 'deritualisation' (Kádár, 2013) - is due to the influence of Western cultures. The significance of our work thus goes beyond the understanding of both food offering in Chinese and Chinese politeness: it adds to the scant literature on the structure of the offering event across cultures and places Chinese politeness in the context of other languages; it brings
\end{abstract}


insights from language contact into the field of pragmatics, a decades-long research paradigm; and it demonstrates the value of diachronic contrastive pragmatics, a direction that will no doubt aid the advancement of contrastive pragmatics in particular and, as a consequence, pragmatics in general.

\section{Keywords}

Food offering - Chinese politeness - contrastive pragmatics - warmth - diachronic contrastive pragmatics - language in contact

\section{$1 \quad$ Introduction}

Comparing and/or contrasting language use across cultures started from the 1980s, a time when pragmatics had just emerged as a legitimate field of investigation. The seminal study on the speech acts of requests and apologies (Blum-Kulka and Olshtain, 1984; see also Blum-Kulka, House and Kasper, 1989), for example, reveals similarities and differences between eight (varieties of) languages. Most recently, Kádár and House (2020a) contrast the apology expressions sorry in English with its Chinese counterpart duibuqi and demonstrate that the former is conventional while the latter is ritualistic in nature (Kádár, 2013). ${ }^{1}$ The study reported in the current paper is a continuation of this research tradition and contrasts the speech event of food offering at the end of a dinner by Southern Californians and the Xi'an Chinese.

End-of-dinner food offering refers to a host asking his/her guest to eat more food when the latter signals that s/he has finished eating. While the actual utterances that are used in the offering and for refusing/accepting are relevant and will be discussed where necessary, they are not our main concern. Our primary focus is the structure of such an event: the number of adjacency pairs that occur during the offering-refusing/accepting sequence and the kind of speech act that is performed at each stage. In other words, we are making a distinction between a speech act that is generally believed to be performed by

1 During the intervening decades, a considerable amount of contrastive research was conducted in all areas of pragmatics: im/politeness (Ruhi and Kádár, 2010; House and Kasper, 1981), discourse markers (Taboada, 2010), political language (Waggoner, 2016) and speech acts such as requests (Hill et al. (1986) in Japanese and English; Chen, $\mathrm{He}$ and $\mathrm{Hu}(2013)$ in Japanese, English and Chinese) and compliment responses (Herbert and Straight (1989) in American English and South African English; Chen (1993) in Chinese and American English; Cordella, Large and Pardo (1995) in American English and Spanish). 
one utterance (Searle 1969, 1975) and a speech event that is made up of several single speech acts.

In addition to the synchronic contrast of American English and Chinese, the current study has a diachronic element. Chen (1996) studies end-of-dinner food offering and finds that his subjects repeatedly offer their guests food, to the point of seeming to 'coerce' them into eating more, with the guests invariably accepting the offer of more food after repeated refusals. ${ }^{2}$ Our study replicates Chen's (1996) methodology so that a contrast can be made between the two populations. To our knowledge, and as demonstrated in the next section, such diachronic contrastive studies are rare in the field. Our paper will hence make a unique contribution to pragmatics in general, and to contrastive pragmatics in particular, by championing a diachronic contrastive pragmatic approach and illustrating one way of undertaking it.

As we will allude to throughout this paper, the linguistic behaviours adopted by the Xi'an Chinese during the act of food offering, as revealed in Chen (1996), are very much ritualistic in nature (Kádár, 2013). The change in the behaviours exhibited by the Xi'an Chinese during the period 1995 to 2019 that we will report can be seen to be a case of deritualisation. Our study, therefore, participates in the study of ritual and is much aligned with the works in Kádár and House (2020b).

In Section 2, we review the relevant literature and Section 3 describes the methodology that we adopt. Section 4 presents and then discusses the findings. In Section 5, we conclude the paper by discussing the theoretical implications of our study.

\section{$2 \quad$ Review of Literature}

\subsection{Literature on the Structure of the Offering Event}

While 'offer' as a single speech act has drawn considerable attention from students of language use (see Barron (2017) for a comprehensive review), 'offer' as an event has been somewhat neglected. There appear to be only three existing studies, including Chen (1996), which we will review below.

Grainger, Mansor and Mills (2015) compare how an offer is conducted in Arabic and English, and find that Libyan Arabic speakers make the same offer at least twice. The first time the offer is made it is generally refused. The host then offers again (and sometimes more than once) before the offer is eventually

2 Due to the repetition of the offering, Chen (1996) names this event 'food-plying'. 
accepted or refused. In one of their examples, the host of a party offers a piece of cake three times, before eventually giving up. To the authors, the reason for this repeated offer is the importance of hospitality, that is, "the host's need to conform to the social convention of appearing generous and the guest's need to not appear greedy" (p. 67). As a result, "the host's behavior typically conveys generosity and warmth, whilst the guest's refusal displays humility and self-restraint" (p. 66). British English speakers, on the other hand, are different. They may repeat the offer, but much less persistently, which the authors attribute to "the rights to autonomy" (p. 66) in British culture.

Zhu, Li and Qian (2000) study gift offering in Chinese within the framework of conversation analysis. The majority of their ethnographical data displays the following sequential structure.

(1) A: Presequence (Optional)

B: Presequence (Optional)

A: Offer, with structural marking (Structural marking optional, if presequences have been used)

B: Decline

A: Offer repeated

B: Decline repeated (Optional)

A: Offer repeated (Optional)

B: Acceptance

(Zhu, Li and Qian, 2000: 98)

This structure is similar to that in Arabic: the offering event is composed of several adjacency pairs (about three in each case) and a set of fixed speech acts, most notably the act of offering and of refusal (decline, according to them). However, they do not consider politeness when accounting for their findings. Instead, they propose that the notions of sincerity and balance are responsible for the offering behaviour of their subjects. The rather complicated sequence helps to ensure the sincerity of the offer. It also provides an opportunity to balance conflicting needs. For the gift giver, that balance is "between not imposing an unwanted gift onto someone and protecting the recipient's face by not suggesting that the recipient is in need of certain things". For the gift recipient, the balance is "between not hurting the gift offerer's feelings by rejecting the offer outright, and not showing greediness by accepting it straightaway" (pp. 99-100).

The third and final study to be reviewed in this section is Chen (1996), who investigated end-of-dinner food offering by Chinese speakers in Xi'an, the 
capital of Shaanxi Province. We will discuss this study in much greater detail: not only will we present his findings and arguments, but also describe his methodology, as this study is the basis for the diachronic component of our paper.

Chen studied dining situations which involved a guest and a host. The host either invited his/her guest to dine in a restaurant (and paid for the dinner) or to his/her home and prepared the dinner herself. Such an invitation was extended for a variety of reasons, but was centred on two purposes: to express gratitude for a favour carried out by the guest or to maintain/enhance the host's relationship, either familial or professional, with the guest. The food offering event occurred at the end of the dinner, typically when the guest put down his/ her chopsticks (or silverware) and pushed his/her bowl/plate slightly away to indicate that $\mathrm{s} / \mathrm{he}$ had finished eating. The aim of the study was to determine whether the host would offer food to the guest by asking the latter to eat more and, if so, how such an offering was performed. The data were obtained from eight actual end-of-dinner conversations: five held in restaurants and three held in the host's home. Since the data were collected in 1995, we will use 1995 as a data point in the ensuing discussions. The findings of the study are presented in Table 1 below.

TABLE 1 Frequency of occurrence of Adjacency Pairs (AP) in all eight events ${ }^{\mathrm{a}}$ (Chen 1996:145, with slight formatting alterations

\begin{tabular}{lllllllllr}
\hline & \multicolumn{3}{c}{ Restaurant $(\mathbf{1}-\mathbf{5})$} & & \multicolumn{1}{c}{ Home $(6-8)$} & Total \\
\hline Conversation & 1 & 2 & 3 & 4 & 5 & 6 & 7 & 8 & 8 \\
AP1 & 1 & 1 & 2 & 1 & 2 & 2 & 1 & 1 & 11 \\
AP2 & 1 & 2 & 1 & 1 & 2 & 0 & 1 & 1 & 9 \\
AP3 & 1 & 1 & 1 & 1 & 1 & 1 & 1 & 1 & 8 \\
AP4 & 1 & 0 & 1 & 0 & 1 & 1 & 0 & 1 & 5 \\
TOTAL & 4 & 4 & 5 & 3 & 6 & 4 & 3 & 4 & 33 \\
\hline
\end{tabular}

a Table 1 taken from Chen (1996, p. 145) with slight formatting alterations.

From Table 1, we can observe that at the end of a dinner involving a host and a guest, there is a lengthy back-and-forth flow to the food offering, which Chen called 'food-plying', that includes an average of 4.0 adjacency pairs. Based on data taken from actual conversations, the following structure of the end-ofdinner food offering event emerges: 


\begin{tabular}{|c|c|c|}
\hline AP & TURN, SPEAKER & SPEECH ACT \\
\hline \multirow[t]{2}{*}{$1 \&$} & 1 , host & Offering \\
\hline & 2 , guest & Refusing \\
\hline \multirow[t]{2}{*}{$2 \& *$} & 3 , host & Asserting that $G$ has eaten little \\
\hline & 4, guest & Asserting that she has eaten much. \\
\hline \multirow[t]{2}{*}{$3^{*}$} & 5 , host & Denigrating food or skill, offering \\
\hline & 6 , guest & Praising food or skill, refusing \\
\hline \multirow[t]{2}{*}{$4^{+}$} & 7, host & Offering, "threatening" with offence \\
\hline & 8 , guest & Accepting \\
\hline
\end{tabular}

FIGURE 1 Structure of end-of-dinner food offering by the Xi'an Chinese in 1995 (Chen 1996:147, with slight formatting alterations).

Notes: \&: repeatable; * : position not fixed; +: optional

This structure is illustrated by Example $(2)^{3}$

(2) AP1 T1: H: 老王, 再吃一点。

Lăo wáng zàichīyīdiăn

"Lao Wang, eat some more."

T2: G: 不用 客气, 我吃好了。

búyòng kèqì wǒchīhăole

"Don't stand on ceremony. I've had enough."

AP2 $\mathrm{T}_{3}$ : $\mathrm{H}$ : 你才吃了那么一点。

nǐ cái chī le nà me yī diăn

"But you've had so little."

T4: G: 不, 不。我吃了很多。

bú bú wǒchīlehěnduō

"No, no. I've had a lot."

AP3 T5: H: 饭不好吃, 但总得吃好啊。

Fànbúhǎochī dànzǒngdéchīhǎo ā

"The food is not good. But you have to have enough."

3 Example (2) taken from Chen (1996, p. 145) with slight formatting alterations and the addition of Chinese typographical characters. 
T6: G: 饭很好吃。我再也吃不下了。 fànhěnhăochī wǒzàiyěchībúxià le "The food is delicious. But I can't eat any more."

AP4 $\mathrm{T}_{7}$ : H: 不行。你得再吃点。要不我就生气了。 búháng nǐdézàichīdiǎn yàobúwǒjiùshēngqìle 。 "No. You have to eat more. Otherwise I'll be offended."

T8: G: 好吧。我再吃一点。

hăo ba wǒ zài chī yī diăn

"OK. I'll have a bit more."

Several generalisations emerge from this study about food offering at the end of a hosted dinner in Xi'an, China. First, the food offering event is a lengthy and repetitive process, lasting an average of eight conversational turns, organised into 4.0 adjacency pairs. Second, the internal structure of the event is rather 'tight' and predictable, although there are variations in terms of the positioning and repeatability of some APs. The event starts with the host offering food (AP1 of Figure 1), moves on to whether the guest has eaten enough (AP2) and whether or not the food is good (AP3), and may or may not include AP4, in which the host threatens that he will be offended if the guest continues to refuse the food being offered. Invariably, the guest accepts the offering, although it is only one small bite of food.

The predictability of the food offering event is also seen in the internal structure of the APs. In classical conversation analysis literature, the second part of an adjacency pair is either preferred or dispreferred. Agreement is the preferred second to an assertion, while disagreement is the dispreferred second. In the food offering speech event, however, most seconds (as seen in APs 1 to 3 , Figure 1) are dispreferred. In AP1, the offer is met with a decline; in AP2, the assertion that the guest has eaten little is met with disagreement; and, in AP3, the host's denigration of the food is met with the guest praising it.

An obvious similarity is observed across the Chinese end-of-dinner food offering event as shown in (2), the typical offering event in Arabic (Grainger, Mansor and Mills 2015) and the Chinese gift giving reported in $\mathrm{Zhu}, \mathrm{Li}$ and Qian (2000, schematised in (1)): the structure of all three is complicated and involves a number of adjacency pairs. However, there is a notable difference between the findings on offering in Arabic and English on the one hand, and offering in Chinese on the other: in the former, the offer may or may not be eventually accepted; in the latter, the offer is always accepted. This suggests 
that offering in Chinese - at least when the offered 'goods' are gifts or food at the end of a dinner - are more 'ritualised' than 'conventionalised' (Kádár, 2013).

To offer an account for his findings, Chen conducted an interview with a group of seven speakers in the same city. During the interview, the informants were asked to express their opinions on why the host repeatedly offered the guest food, whether such an offering sounded 'pushy' and why the guest did not accept the food earlier. On the basis of these interviews, Chen proposes that the motivation for the repeated offering of food by the host, as well as the repeated rejection of the offering by the guest, is the concept of warmth, one of the key notions of Gu's (1990) work on Chinese politeness. In other words, the repeated and forceful offering of food, which would appear to be particularly imposing to the guest in the eyes of a cultural outsider, serves the purpose of demonstrating care about the guest's wellbeing, specifically that the host wants the guest to eat well and enjoy the occasion. The economic basis for this particular demonstration of warmth, Chen further argues, was the historical scarcity of food in the region.

\subsection{Literature on Diachronic Pragmatics}

Diachronic pragmatics is a relatively small subarea of pragmatics. Most studies in the field concentrate on specific areas of language use in historical periods of time. Some studies have contrasted two languages in the same period of time, such as Ruhi and Kádár (2010), who investigate the use of the word face in late nineteenth and early twentieth century Turkish and Chinese.

In addition, some contrastive studies have investigated language use over time. Allen (2018) compares lexical bundles found in the language input of a selection of historical (1905-1907) and current (2004-2014) English language teaching material. The collection of papers in Popular News Discourse in American and British newspapers 1833-1988, a special issue of the Journal of Historical Pragmatics, compare and contrast "the various strategies employed by popular newspapers to articulate an idealized version of the interests and language of their readers for profit and political influence" (Conboy, 2014). Lastly, Pan and Kádár (2011) investigate politeness in Chinese, contrasting historical and contemporary periods. The offering of tea at a wedding by the bride to her parents-in-law - an example of contemporary Chinese politeness - for instance, is till ritualized but different from historical Chinese politeness, as there were no honorifics used and the offer sounds "more direct" (pp. 76-77).

These diachronic contrastive studies rely on written data, and for good reason: recorded speech did not exist for much of the history of humankind. However, there is one exception, namely Chen and Yang (2010). Chen (1993) 
finds a marked contrast between Americans and Chinese when responding to compliments. While the Americans, on the whole, accepted the compliments, the Chinese mainly rejected the compliments and self-denigrated when responding to them. Chen proposes that these behaviours were motivated by Leech's (1983) notion of modesty. Chen and Yang (2010) replicated Chen's (1993) work and found that their Chinese subjects no longer used rejection and self-denigration as the main strategies for responding to compliments. Instead, for the majority of the time, they accepted the compliments, much like the Americans. On the basis of interview data, the authors argue that this change was largely due to the infiltration of Western cultures. The diachronic component of our current paper is a continuation of Chen and Yang's (2010) study and replicates Chen's (1996) work to contrast the end-of-dinner food offering behaviour exhibited by the Xi'an Chinese between 1995 and 2019 .

\section{3}

\section{Methodology}

Two sets of data are used for the current study: American and Chinese. The American dataset was collected in Southern California during dinners at home, to which the host had invited a guest (or guests). A total of 10 conversations were collected, but only eight were randomly chosen to match the number of conversations that were analysed in Chen (1996). Six of these eight conversations were audio-recorded, with consent being given for the recording by each of the participants. Two conversations were written down from recollections immediately after the event and were then verified (and approved for use) by the participants.

All eight dinner conversations took place at the hosts' homes, with the food being either prepared by the host or ordered in from restaurants. The absence of restaurant dinners is because of the way food is served in American restaurants: each diner orders their own food, which is then served on plates specifically for that diner. It would therefore be very unlikely that the host would offer his/her guest(s) food at the end of the dinner (except for making enquiries about dessert). The age of the participants ranged from 34 to 67 and the number of participants varied from two to seven. In terms of gender, two of the eight dinners were attended only by men, two only by women and four by mixed gender groups. In terms of the occasion, three dinners were birthday parties, two were Thanksgiving dinners, one was a Christmas party and the remaining two were get-togethers. Information about the American dataset is given in Table 2. 
TABLE 2 Information about the American dataset

Total number of $\quad 8$ (randomly chosen from 10); audio-recorded 6, written down 2 conversations

Venue All at the hosts' homes

Participants Ages 34-67; range: 2-7; all-male 2; all-female 2; mixed-gender 4; total 29

Occasion Birthday 3, Thanksgiving 2, Christmas 1, get-together 2

Data on the food offering behaviours of the Chinese living in the Xi'an area were collected in a similar way, and the relevant information is summarised in Table 3 .

TABLE 3 Information about the Chinese dataset

Total number of 8 (randomly chosen from 9); audio-recorded 5, written down 3 conversations

Venue Restaurants 6; at the hosts' homes 2

Participants Ages 25-68; range 3-5; all-male 2; all-female 1; mixed-gender 5; total 31

Occasion Birthday 2, Mid-Autumn 1, ${ }^{\text {a }}$ thank-you 2, get-together 3

a A festival that falls on the 15th day of the 8th month of the lunar calendar that celebrates the reunion of families.

Much of the information provided in Tables 2 and 3 above will not be pursued in the remainder of this paper, as we are not concerned with all the factors detailed in them, such as gender. ${ }^{4}$ The venue and occasion might have been relevant to our goals, but no difference was found in either Chen (1996) or in our current analysis. ${ }^{5}$ However, we acknowledge that the demographics of the participants could be relevant in a larger dataset. In Section 5 , we will discuss how focusing on the participants can help us with further research on this topic.

4 In terms of the language used, six of the conversations were conducted in Mandarin and two in Xi'an dialect. Since the differences between Mandarin and Xi'an dialect are primarily phonological and most speakers of Xi'an dialect also speak Mandarin, we do not believe that the actual dialect used in the conversations has any bearing on our findings.

5 This lack of a difference may be due to the number of conversations in our datasets. 
Once the data were collected, transcribed, and analysed, the structure of food offering in each of the two datasets emerged, as presented in Table 5 (Section 4.1) and Table 6 (Section 4.2).

Also following Chen (1996), the native speakers' views on their food offering behaviour were obtained from face-to-face interviews and email surveys by using a simple questionnaire (see the Appendix) as a prompt. For the American group, three interviews were conducted with eight dinner participants and the questionnaire (see the Appendix) was sent to all 29 dinner participants, with 21 returning the survey. For the Chinese group, two interviews were conducted with a total of seven dinner participants and the questionnaire was sent to all 31 dinner participants, with 23 responding. This gathering of qualitative data is summarised in Table 4, below.

TABLE 4 Interviews and email surveys

\begin{tabular}{lll}
\hline & American & Chinese \\
\hline Interview & 3, with 8 respondents & 2, with 7 respondents \\
Email survey & Sent to 29, received 21 responses & Sent to 31, received 23 responses
\end{tabular}

These responses will form the foundation of our discussion on the findings of the study, which will be detailed in Section 4 below.

\section{Findings and Discussion}

\subsection{American}

Following Chen (1996), the number of conversational turns and adjacency pairs in each end-of-dinner food offering are reported. Table 5 presents the findings obtained from the American data.

TABLE 5 Findings obtained from the American data

\begin{tabular}{llllllllll}
\hline Conversation & 1 & 2 & 3 & 4 & 5 & 6 & 7 & 8 & Average \\
\hline Number of APS & 1 & O & 2 & O & o & 1 & o & 1 & $5 / 8=0.63$ \\
\hline
\end{tabular}


Of the eight end-of-dinner conversations in the data, there were only five instances where more food was offered at the end of the dinner, with these occurring in four of the eight conversations. Food offering did not take place during the other four conversations. This suggests that food offering is not a particularly frequent occurrence during dinners hosted and attended by the American residents of Southern California.

By examining the food offering conversations, we discover that Americans offer food rather succinctly, as shown in Example (3) below:

(3) [Thanksgiving party. There are four invited guests: two married couples. The host is female and she has cooked the meal.]

Host:[Seeing that one guest, John, has put down his fork] More turkey, John?

Guest: Oh no. Thanks.

Host: OK. [Resumes the prior topic of conversation concerning the quality of local public schools.]

(American Conversation 1)

The offering of food is achieved with 'More Turkey' and the declining of the offer with 'Oh no', followed by 'thanks'. The host immediately stops offering food after the declination.

In Example (4), the offer of food is carried out indirectly.

(4) Host: [To all the five guests at a birthday party for her husband Josh]: Hope y'all like the food.

Guest: [While other guests simultaneously praise the food with exclamations ("yum yum"), gestures (thumbs up, okay sign), and nods of heads] I did not know you are such a good cook - everything's delicious! Josh is a lucky man indeed.

Host: I'm glad. There is more - a lot more. Nobody is stopping you from getting a second or even a third serving.

Guest: I would love to, but there is no space left in the stomach [slightly massaging his stomach with both hands].

(American Conversation 6)

This excerpt of conversation begins with the host enquiring about the quality of the food, as if she is 'fishing for a compliment'. While all the guests compliment the food in different ways, John goes further by praising the food with lengthy utterances ('I did not know ...'). This creates the opportunity for the host to offer him food. However, she does not make the offer directly, e.g. with 
an imperative sentence such as 'Take more then', but instead says, 'Nobody is stopping you from getting a second or even a third serving.' This statement is what Searle (1975) would call the indirect speech act of offering and Brown and Levinson (1987) would call an 'off-record' politeness strategy for the purpose of mitigating the face-threat entailed in the act of offering. Indeed, the guest takes it as such and declines the offer with the account, 'No space left in the stomach.'

The most elaborate form of food offering is shown in Example (5), in which two adjacency pairs are devoted to the act of food offering.

(5) [A get-together of friends after one of them - Guest below - has been away for two years. The food is a takeout from a local restaurant, which has been placed in the kitchen adjacent to the dining room.]

Host: [Seeing that the Guest puts down his fork and pushes his plate slightly away] Hey, don't stop yet. There's plenty of food there. You got to help me with all that good stuff.

Guest: [Hesitates] Well.... But.... Not sure it'll be a wise thing to do.

Host: Look at you - a couple of more pounds will make you look even more attractive.

Guest: That is itself an attractive proposition. For the heck of it. [Stands up and walks to the kitchen for another serving.] (American Conversation 3)

The first adjacency pair starts with the host offering food in a 'bald-on-record' way, with imperative sentences such as '... don't stop yet' and 'You got to help me with all that good stuff.' The refusal of that order-like offer comes after a slight hesitation on the part of the guest, who seems to be in two minds about the offer: 'Not sure it'll be a wise thing to do.' The host starts the second adjacency pair with 'Look at you ...' and then goes on to offer the guest some food by making a veiled reference to the guest's supposed thin figure. The guest takes the food, agreeing that eating more food is good for his appearance ('that is itself an attractive proposition'). These two adjacency pairs reflect the participants' efforts to create positive politeness between themselves, and they aim to reduce the face threatening force of the offer by the use of joking, a strategy that often helps create camaraderie and in-groupness (Brown and Levinson, 1987).

The behaviours exhibited by the Southern Californians during end-ofdinner food offerings appear to be accountable to Brown and Levinson's politeness theory. According to Brown and Levinson (1987: 66), offering is a face-threatening act (FTA) in that it forces the hearer to decide whether to 
accept or refuse an offer. By accepting an offer, the hearer becomes indebted; refusing it makes the hearer appear disagreeable. ${ }^{6}$ Therefore, it seems justifiable to propose that the food offering behaviour exhibited by the Americans is due to their need to avoid the imposition that the act of food offering entails. When they do make an offer, they do so indirectly, often adopting 'off-record' strategies or positive politeness strategies, both of which help them mitigate the face threatening force of the offering act.

As discussed in Section 2.1, Grainger, Mansor and Mills (2015) hold that British offering behaviour is due to the speakers' "rights to autonomy" (p. 66). Although the authors choose not to use Brown and Levinson's politeness theory to account for their data, the 'rights to autonomy' is obviously synonymous to Brown and Levinson's notion of 'freedom from imposition', one of the two pillars on which their entire theory rests.

Our argument that Brown and Levinson's (1987) theory accounts for our findings on American food offering behaviour is verified by our interviews with eight dinner participants and the responses to our email survey from 21 participants. The results of these interviews and email surveys are summarised below.

First, almost all the 29 respondents - eight interviewees and 21 email survey respondents - expressed surprise at Chen's (1996) findings, with 'Wow' being a common exclamation. However, one interviewee noted that he had actually experienced Chen's kind of 'food-plying' himself while travelling in China during the late 1980s: 'Yeah. My host pressed and pressed and I realized I was not to be let go without eating a bit more,' he recalled. 'I really appreciated my host's good intention: to make sure I was taken care of.'

The interviewees and survey respondents provided several reasons as to why they did not frequently engage in end-of-dinner food offering themselves. Firstly, 'There doesn't seem to be a need.' Thirteen of the survey respondents reported, in different ways, that dinner is not a 'big deal' in their culture. 'You invite someone. They come, eat, and talk. When they finish, it means they have had enough. Why bother to ask them to eat more?' one respondent wrote in her email. Others echoed that food is only one part of the dining event: 'Talking, catching up, enjoying the company, are just as important.' One interviewee and two survey respondents did say, however, that they would offer food to their guests 'just to make sure that they are not being

6 An offer may not always be this face-threatening, as it also depends on whether the hearer needs the goods being offered and how the offer is performed. In a London subway station, the first author was struggling with luggage and was on the verge of asking for help, when a young man came over and asked: 'Would you be happy if I carried this for you [pointing at a piece of luggage], would you?' The first author did not feel that his face was threatened and we doubt that anyone would. 
bashful' about eating in front of others. Two survey respondents reported that some occasions might call for the offering of food more than others. One of these respondents emphasised that 'If I am hosting a dinner to thank someone for a favor, I think I might just ask if they want more of something.'

Second, not to offer food can be regarded as being 'considerate' of other people's tastes. One of the interviewees said the following, winning nods of approval from two others present.

I think there is also a matter of ... well ... if your guest likes the food. Eating is a private experience, I think. We like vastly different things. We don't want to force our guests to eat something they are not particularly fond of. If they don't like what you want them to eat, they cannot say "Sorry, I hate it," right?

The same view was also expressed by the email survey respondents. One of them jokingly wrote: 'Remember the cliché “One man's meat is another man's poison." You never know. What you like can be absolutely disgusting to someone else.'

If that is the case, why did the host in Example (5) offer her guest food the second time? We asked the host this question during one of the face-to-face interviews. After the host was shown the transcript of the conversation, she recalled: 'Oh, I got it. He [the guest] was hesitant in his refusal, indicating that he could eat more.' The host was then asked, 'Are you saying that if he assertively refused your offer, you would not have attempted a second try?' 'I believe so,' she replied.

Thirdly, one should not be offering food because 'You just don't know that some people may be dieting or have health reasons.'

During the three interviews, we also asked the interviewees if they could imagine themselves repeatedly offering food to guests, in much the same way as Chen's (1996) subjects did, to which all the interviewees emphatically replied that they would not. When we enquired further into the reasons for not doing so, one interviewee replied, "That would not be right in our culture. You would be appearing to be too much of a pusher.' Another interviewee responded with 'That would be quite inconsiderate of how the guest feels', while a third respondent thoughtfully added, 'Well, that does not mean that the Chinese are rude, though. We know each culture is different.'

\subsection{Chinese}

The findings on food offering by the Xi'an Chinese are given in Table 6 . 
TABLE 6 Findings obtained from the Chinese data

\begin{tabular}{llllllllll}
\hline Conversation & $\mathbf{1}$ & $\mathbf{2}$ & $\mathbf{3}$ & $\mathbf{4}$ & $\mathbf{5}$ & $\mathbf{6}$ & 7 & $\mathbf{8}$ & Average \\
\hline Number of APs & $\mathrm{O}$ & $\mathbf{1}$ & 2 & $\mathrm{O}$ & $\mathbf{1}$ & 2 & 0 & 1 & $7 / 8=0.88$ \\
\hline
\end{tabular}

The Xi'an Chinese are found to offer their guests food by using an average of o.88 adjacency pairs per dinner. Of the eight conversations in the data, it can be observed that food offering does not place in three of them (Conversations 1,4 and 7 ). Of the five that do include food offering, the number of adjacency pairs ranges from one (Conversations 2, 5 and 8) to two (Conversations 3 and 6). In the following, four examples are provided, two with one adjacency pair and two with two adjacency pairs.

(6) [A get-together of five participants. The dinner is prepared by the host at his home.]

Guest: [Puts down his chopsticks, signalling he has finished eating.] 你的饭 做的 真好.

nǔdefàn zuòde zhēn hăo

"You are such a good cook."

Host: 好吃 就要 再吃一些。来, 我给你夹。 [Starting to serve food.]

hăochī jiùyào zàichī yīxiē lái wǒ gěinǐ jiá

"Since you like it, you should have more. Come on. We will get more for you."

Guest: 好. 谢谢。就 再来一点。 hăo xièxiè jiù zàilái yīdiǎnr

"Sure. Thanks. Just a little bit."

(Chinese Conversation 2)

In this example, the offering of food appears to be precipitated by the guest's compliment of the host's food. The host tacitly accepts the compliment and uses it as a reason to offer the guest more food. It should be noted that the host begins serving before his offer is accepted, but the guest accepts the offer without much hesitation.

The offering in Example (7) also has one adjacency pair, but this time the offer is not accepted. 
(7) [At a restaurant. Two participants are invited by the host]

Host: [Seeing both guests stop eating and push their plates slightly away.]

吃好了吗? 再来一点 吧?

chīhǎo le ma zàilái yīdiǎnr ba

"Have you had enough? A bit more?"

Guestı: 好啦。谢谢。

hǎolā xièxiè 。

"I'm good. Thanks."

Host: [To Guest2]

你哪?

nǐ nǎ

"How about you?"

Guest2: 我也吃好啦。不客气。

wǒ yě chīhǎo lā bú kèqì

"I have had enough as well. Thanks."

Host: 好。那就边喝茶边聊吧。

hăo nàjiù biān hēchá biān liáo ba 。

"OK. Let's continue to talk while drinking tea."

(Chinese Conversation 8)

The host offers food twice because there are two guests, but each guest is only offered food once, and hence this conversation is counted as having one adjacency pair. When the host notices that the guests intend to stop eating, he asks both of them to have some more food. Both guests decline and the host stops the offering, but instead asks the guests to continue drinking their tea.

The following examples illustrate two adjacency pair food offerings.

(8) [In an upmarket restaurant. The dinner was intended to be a token of appreciation in return for a sizeable favour that the guest has done for the host.]

Host: 我们 说话 不要耽误吃饭。我来给您再夹些鱼。 wǒmen shuōhuà búyàodānwù chīfàn wǒ lái gěinín zàijiáxiēyú "Let's not allow talking to hinder eating. Let me serve you more fish." 
$\begin{aligned} & \text { Guest: } \text { 不用了。我吃 好了。 } \\ & \text { búyòngle wǒchī hăo le } \\ & \text { "No. I have had enough." }\end{aligned}$

Host: 李先生, 再来 点吧. 您 为这事 累了一整天。多吃一点, OK?

lǐ xiānshēng zàilái diănba nín wéizhèshi lèile yīzhěngtiān duōchī yīdiăn oK

"Mr. Li, just a bit more. You have been working on this for the whole day. Just a bit more, ок?

Guest: 好吧。一点 就行。

hăoba yīdiăn jiùxíng

"ок. Just a bit."

(Chinese Conversation 3)

In the first food offering adjacency pair, the host's offer of more fish is refused (Guest: 'No. I have had enough'). The host then tries offering food a second time, but this time giving a reason: 'You have been working on this for the whole day.' The guest relents and accepts the offer by saying, 'OK. Just a bit.'

(9) [At the host's home. A small alumni gathering of five in honour of the guest who has been away from the group for nine years.]

Guest: 谢谢李学姐, 做了这顿美餐。太好了。

xiè xiè lǐ xué jiě, zuò le zhè dùn měi cān tài hăo le

"Thank you so much, Sister Li. You have cooked such a fantastic dinner. Wonderful."

Host: 好吃就要多吃。接着来。

hăo chī jiù yào duō chī jiē zhe lái

"Since you like it, eat more."

Guest: 好了。就此打住。

hăo le jiù cǐ dă zhù

"I'm good. I'm stopping."

Host: 你叫我姐姐, 我就要照顾你。听话, 啊?

ny̌ jiào wǒ jiě jiě wǒ jiù yào zhào gù nǐ tīng huà ā?

"As your sister, I should take care of you. Listen to your sister, ок?" 
Guest: 亲爱的姐姐, 饶了我吧, 真不行了。 qīn ài de jiě jiě, ráo le wǒ ba, zhēn bú háng le "My dear sister, please forgive me, I really can't."

Host: 好吧, 饶了你。

hăo ba, ráo le nǐ.

"Ок. You are forgiven."

(Chinese Conversation 6)

In addition to the offering of food at the end of a dinner, the data collected in this study also reveal an aspect that was not discussed in Chen (1996): during the dinner, the host is found to serve food from serving plates located in the middle of the dining table, placing the food onto their guests' individual plates or bowls. While serving food in this way during a dinner is not an end-of-dinner offering per se, it is related to offering in that it shows care and warmth towards the guest, a point which we will return to later in the paper.

In summary, the Xi'an Chinese in the current study are found to offer food much less often than their counterparts did in 1995 (as reported in Chen (1996)). As shown in Figure 2 (Section 4.3), they now use an average of less than one adjacency pair (o.88) in an end-of-dinner food offering (as opposed to 4.0 in 1995, see Figure 1). Even though the number of conversations recorded is too small to draw a statistical significance, the decrease in the number of adjacency pairs from 4.0 to 0.88 is rather substantial.

The manner in which the offering is performed has also changed. As shown in Figure 1, the structure of food offering at the end of a dinner that was identified in Chen (1996:147) includes adjacency pairs such as "host asserting that guest has eaten little/guest asserting that she has eaten much"; "host denigrating food or skill, offering/guest praising food or skill, refusing"; and "host offering, 'threatening' with offence/guest accepting." These adjacency pairs would appear to be particularly imposing to the guests, which led Chen to propose that the purpose of this practice is for the host to demonstrate warmth $(\mathrm{Gu}, 1990)$ and care for his/her guests. However, none of these three types of adjacency pair occurred in the 2019 dataset. Instead, the way in which food is offered is much less direct. In Example (7), for instance, the host offers food by asking the question 'A bit more?' (rather than 'You must eat more!') and, after the guest declines the offer with 'I'm good. Thanks', the host unceremoniously stops offering. Even in the two conversations that have two adjacency pairs in the offering, the tone is much different. In Example (8), the second offering is performing by the host asking 'ок?', leaving the guest some room to refuse 
the offer. In Example (9), the first offer is tagged to the host's compliment of the food, 'Since you like it, eat more.' In the second adjacency pair, the offer is rendered in a joking manner, 'As your sister, I should take care of you. Listen to your sister, ok?' The use of the kinship term and the jocular tone are typical of positive politeness strategies, serving to establish in-groupness and hence reducing the threat to the guest's negative face.

Lastly, the result of the offer is also different in the two groups of Chinese participants. As previously noted and shown in Figure 1, the guest always accepts the offer in 1995. This indicates that both the host and guest are aware that the lengthy offering sequence - particularly the refusals in it - are for ritual purposes (Kádár, 2013). However, in our 2019 data, several offers end up with the guest not accepting the offer. This process of deritualisation coincides with a pattern identified by Pan and Kádár (2011) regarding the general notion of Chinese politeness.

How can we explain these changes in the end-of-dinner food offering behaviour of the Chinese living in the greater Xi'an area? To answer this question, we now turn to the findings of our interviews and email surveys.

As shown in Table 4 above, seven Chinese speakers were interviewed and 23 responded to our email survey. When we summarised our findings, represented pictorially in Figure 2 (Section 4.3) - that is, the Xi'an Chinese clearly perform far fewer food offerings in 2019 than in 1995 - none of the interviewees or survey respondents were surprised, with many of them replying with the sentiment 'That makes sense'. A few of the survey respondents in their late twenties and early thirties noted that they could believe the findings as reported in Chen (1996), but they were too young to have experienced life in the mid-199os.

Chen (1996) proposed that the historical scarcity of food in China could be the economic reason for the repeated food offering at the end of a dinner: the host wanted to ensure that the guest ate well. This proposal received strong support from the interviewees and survey respondents. Seven of them - all aged in their late 5os and early 6os-commented on Chen's (1996) findings by saying that 'People were offered food in that way in the 199os because the country was just beginning to get out of poverty' and 'People had not had enough to eat for a long time, and they needed to make sure that their guests were having enough at their dinners.'

But the question remains: Why do the Xi'an Chinese now perform far fewer end-of-dinner food offerings? The interviewees and survey respondents provided two reasons for this finding. The first is the change in the economy. 'Food is everywhere and nobody is starving anymore,' one interviewee confidently declared, with five other survey respondents making similar observations. 
Second, the Chinese perception of politeness is now different. It was found that the Chinese used the act of food offering at the end of a dinner to demonstrate warmth and care for their guests in 1995, but several respondents wrote in their email surveys that 'there doesn't seem to be a need for that nowadays, as people are more casual in their relationships.' Third, Western cultures may have influenced the linguistic behaviour of the Chinese in general. Five respondents who had lived outside China, particularly in Europe and America, admitted that they changed their verbal behaviours in noticeable ways, towards being less 'imposing' and more individualistic. The majority of the email survey respondents and the interview participants agreed with this change in verbal behaviour. During one of the interviews, a participant - not one of the five who had lived overseas - observed:

I remember those old days when we literally forced people to eat, particularly in rural areas. But that seems to be old-fashioned now. You now see all kinds of 'foreigners' on the streets of Xi'an and everywhere. Their way of doing things is influencing us. Your figure shows that Americans do not offer food at the end of a dinner very much, and it makes sense, as American culture is exerting its influence on Chinese culture ... films, songs, clothing, technology, you name it.

In keeping with the American respondents, our Chinese respondents mentioned the need to consider the guests' food preferences. Three respondents commented on the possibility that their guests were on particular diets: 'Women, especially young women, are careful about what and how much they eat.' Two respondents mentioned 'greenness': 'You never know. Some people are picky about eating "green" food. You don't want them to feel they have to eat what they find morally objectionable.'

As alluded to earlier, serving food onto each guest's individual plate occurred during six of the eight conversations in our data. Several respondents opined that this is also a way of portraying warmth and care. Two respondents expanded on this, by saying that when doing so, they would only serve food that they knew the guest would like. If they were not sure of the guest's food preferences, they would enquire before serving. Indeed, in the six conversations during which serving actually took place, there were three instances where the hosts asked their guests whether they liked a particular dish before serving them. In two of these instances, the hosts later responded that they only served those foods which they knew their guests liked.' As one of the respondents explained, 'I knew their habits well.' 


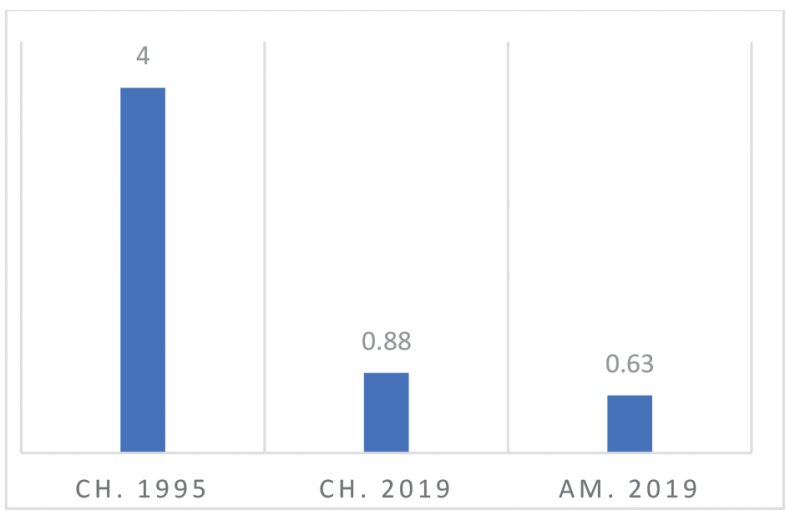

FIGURE 2 A three-way comparison

\subsection{Three-Way Comparison/Contrast}

It is evident that the ritual of food offering in Chinese settings has been significantly weakened over the past 24 years, almost to the point of non-existence, ${ }^{7}$ as can be clearly seen in Figure 2 below (in which the numbers above the bars are numbers of adjacency pairs for each group).

In Figure 2, each column represents the average number of adjacency pairs that occurred in the food offering event for each studied population group, and two generalisations can be made from this graph. First, the food offering behaviours of the Chinese groups appear to have undergone a significant change, from having 4.0 adjacency pairs in 1995 to 0.88 adjacency pairs per dinner conversation in 2019. Second, in comparison to the Chinese, Americans conduct far fewer food offerings, with an average of 0.63 adjacency pairs per dinner conversation.

In this section, the quantitative results - although no statistical significance is claimed because there are only eight conversations in each dataset - as summarised in Figure 2, are discussed in light of politeness theories as well as the input derived from native speakers through the use of interviews and email surveys.

The current three-way comparative/contrastive study of end-of-dinner food offering has revealed three findings. First, Americans living in Southern California do not frequently offer their guests food at the end of a dinner, as indicated by an average of 0.63 adjacency pairs per dinner conversation. Second, the Chinese residents of Xi'an offer their guests food more frequently than the Americans, averaging o.88 adjacency pair per dinner conversation,

7 Whether this ritual still exists is a matter of debate. 
although we do not attest the statistical significance of this difference because of the sample size. Third, the food offering behaviour of the Xi'an Chinese has undergone a notable change between 1995 and 2019. Instead of repeatedly and forcefully offering their guests food, they now offer food far less often. As of 2019, their end-of-dinner food offering behaviour more closely mirrors that of the Americans than the behaviour of their Chinese counterparts in 1995 .

The findings on Chinese food offering in 1995 were attributed to the notion of showing warmth and care by Chen (1996), hallmarks of Brown and Levinson's (1987) positive politeness. The findings obtained from the American group, as reported and discussed in this study, suggest that the American act of food offering (or the lack of it in half the dinners in the data) is influenced by a need to avoid and mitigate the threat that the speech act of food offering entails to the negative face of the guest, that is, the desire to be left alone. The Chinese offering behaviours as of 2019, therefore, suggest a change in politeness: more weight is now being given to negative politeness. This diachronic change is, in part, attributed to the influence of Western cultures, as indicated by our interviewees and survey respondents. It should be noted that this change does not appear to be an isolated occurrence.

In this sense, the current study agrees with Chen and Yang (2010). Both studies have found that a change has occurred between the two Chinese groups, away from traditional, native cultural values and towards Western cultural values. The input received from the subjects and respondents in both studies has identified the influence of Western cultures as being the catalyst for these changes.

\section{5}

\section{Conclusion}

Contrastive pragmatics is invaluable for discovering the similarities and/or differences between cultures and languages about a particular linguistic reality. This study, we believe, has achieved that goal by revealing the similarities and differences in end-of-dinner food offering events across three population groups. As we have indicated throughout this paper, our work complements the existing literature on ritual by showing how, on the basis of natural language data, the ritual of food offering has been 'deritualised', a point made by several authors in Kádár and House (2020b).

In addition, this study has several important theoretical implications. In this concluding section, we will discuss two of these: the implications for politeness research and the implications for diachronic contrastive pragmatics. 
In the previous discussion, the findings on American food offering were attributed to the speaker's adherence to negative face. Chen's (1996) findings on Chinese food offering in 1995 were attributed to the notion of warmth, which is essentially a positive politeness strategy. The difference between these two groups might lead to the conclusion that the Chinese and the Americans follow different principles in politeness, which might, in turn, lead to doubts about a universal notion of politeness (see Chen (2010) for a comprehensive review on the East/West divide debate). We contend, however, that neither assertion is accurate.

The contrast between Chinese food offering in 1995 and American food offering in 2019 - for the sake of argument we are comparing two populations in different time periods, being fully aware that such a comparison, in itself, is invalid - is a contrast in only the speech act of food offering at the end of an invited dinner. It should not be viewed as a contrast in the speech act of offering in general, let alone a contrast between politeness in the two cultures. Tannen (1986: 106-108) records a conversation between an American widower and his stepdaughter and step son-in-law at a picnic. Suffering from the recent loss of his wife, the elderly widower refuses to eat. The young couple repeatedly try to persuade him to eat. They cajole, lure and coerce the elderly widower on over ten occasions during the course of the picnic, far more times than Chen (1996) reports the Chinese doing. Although this is an isolated instance, this example reveals why it is dangerous to make sweeping assertions about the politeness of a culture.

Similarly, the contrast revealed in the current study should not be seen as evidence against a universal theory of politeness. Brown and Levinson (1987), for instance, can be used to account for both the 1995 Chinese data and the 2019 American data. The repeated offering of food by the Chinese in 1995 - a demonstration of warmth - is motivated by the host's need to cater to the guest's positive politeness: the wish to be liked, appreciated and cared for. The infrequency and indirection of the end-of-dinner food offering by the 2019 American population are motivated by the host's need to cater to the guest's negative politeness: the claim to territory and freedom. Of course, both notions are taken from Brown and Levinson, thus indicating that their theory can account for the data obtained in both these population groups.

In Section 3, we acknowledged that the size of our datasets may have obscured the role played by speaker demographics in the linguistic behaviour observed, but this caveat of our investigation can be mitigated by further research. For example, a larger dataset might reveal that age is a significant factor, particularly diachronically, as age itself is diachronic. The same might be expected of gender: dinners tend to be intimate social settings and, in 
literature, gender has been shown to be a factor in how speakers perform speech acts in these situations.

Second, we believe that our study makes a significant contribution to historical pragmatics. In fact, it points to the possibility of diachronic contrastive pragmatics. For the most part, contrastive pragmatics research has been conducted synchronically: two or more target populations from the same historical period of time are compared/contrasted. Historical pragmatics, as we discussed in Section 2.2, focuses on language use in a period of time in history. In the rare cases in which a topic has been approached contrastively (e.g. Allen, 2018; Conboy, 2014; Pan and Kádár, 2011), the data are drawn from written sources. The reason for this is clear: authentic data on language use in the past are hard to obtain. For instance, if we were to study how speakers apologised in rural Yorkshire during the Victorian era, it might not be easy because there is just no authentic data. However, the field of pragmatics has long since grown out of its infancy and empirical studies, with real-life or quasi real-life data, began more than thirty years ago during the 198 os. We therefore end the current study by echoing Chen and Yang's (2010) call for diachronic contrastive pragmatics, as we are convinced that looking at pragmatics over time will offer unique insights into how language and social values change and how language and culture can influence each other when they come into contact. Zhu, Li and Qian (200o), for example, find that the gift offering and acceptance sequence in Chinese follows a similar pattern, that the giver and recipient undertake several rounds of negotiation before the gift is eventually accepted. But this study was conducted two decades ago. Wouldn't it be interesting to investigate whether the Chinese have changed their linguistic behaviours in gift offering and acceptance as well?

\section{Appendix}

To the American respondents: Thank you very much for giving us permission to use the conversation that you participated in during the dinner held on [DATE]. The purpose of our study is to compare/contrast the linguistic behaviours exhibited when offering food to guests at the end of a dinner between the Chinese (two population groups: 1995 and 2019) and the Americans. So, for example, when you invite some friends to a dinner, you might ask your guests whether they would like more food when they put down their silverware. You might also offer food to them by saying something like, 'Would you like more?'

The following figure [Figure 2 of the current paper, omitted herein] is a summary of our findings. The numbers given for each group are the average number of adjacency 
pairs for each conversation. 'Adjacency pair' is a term referring to two utterances that are grouped together, such as 'Thank you' and 'You're welcome'. The number o.63 evaluated for the American 2019 group means that, on average, each conversation in our study (there were a total of eight American conversations) includes 0.63 food offering adjacency pairs.

As you can see in this figure, Americans perform far fewer end-of-dinner food offerings than the Chinese, particularly when compared with the Chinese data obtained in 1995. We would like to know your thoughts on this: why do you, as an American, only offer food infrequently on these occasions?

To the Chinese respondents [Original in Chinese]: Thank you very much for giving us permission to use the conversation that you participated in during the dinner held on [DATE]. The purpose of our study is to compare/contrast the linguistic behaviours exhibited when offering food to guests at the end of a dinner between the Chinese (two population groups: 1995 and 2019) and the Americans. So, for example, when you invite some friends to a dinner, you may ask your guests whether they would like more food when they put down their chopsticks. You may also offer them food.

The following figure [Figure 2 of the current paper, omitted herein] is a summary of our findings. The numbers given for each group are the average number of adjacency pairs for each conversation. 'Adjacency pair' is a term referring to two utterances that are grouped together, such as 'Thank you' and 'You're welcome'. The number o.63 evaluated for the American 2019 group means that, on average, each conversation in our study (there were a total of eight American conversations) includes 0.63 food offering adjacency pairs.

The 2019 Chinese group, of which you were a part, is found to perform the act of food offering much less frequently than the 1995 Chinese group reported in an earlier study (Chen, 1996): for an average of o.88 adjacency pairs in 2019 (as opposed to 4.0 in 1995). We would like to know your thoughts on this: why do the Chinese now perform fewer food offerings at the end of a dinner than 24 years ago?

\section{References}

Allen, Rachel. 2018. Dialogues in diachrony: Celebrating historical corpora of speechrelated texts. Journal of Historical Pragmatics 19(2): 167-185.

Barron, Anne. 2017. The speech act of "offers" in Irish English. World Englishes 36(2): $224-238$.

Blum-Kulka, Shoshana, and Elite Olshtain. 1984. Requests and apologies: A cross-cultural study of speech act realization patterns (CCSARP). Applied Linguistics 5(3): 196-214. Blum-Kulka, Shoshana, Juliane House, and Gabriele Kasper (eds.). 1989. Cross-cultural Pragmatics: Requests and Apologies. Norwood, NJ: Ablex Publishing Corporation. 
Brown, Penelope, and Stephen Levinson. 1987. Politeness: Some Universals in Language Use. Cambridge: Cambridge University Press.

Chen, Rong. 1993. Responding to compliments: A contrastive study of politeness strategies between American English and Chinese speakers. Journal of Pragmatics 20(1): 49-75.

Chen, Rong. 1996. Food-plying and Chinese politeness. Journal of Asian Pacific Communication 7(3-4): 132-155.

Chen, Rong. 2010. Pragmatics between East and West: Similar or different? In: Anna Trosborg (ed.), Pragmatics across Languages and Cultures. Berlin/New York: Mouton de Gruyter, $167-188$.

Chen, Rong, and Dafu Yang. 2010. Responding to compliment in Chinese: Has it changed? Journal of Pragmatics 42: 1951-1963.

Chen, Rong, Lin He, and Chunmei Hu. 2013. Chinese requests: In comparison with American English and Japanese and with reference to the "East-West divide". Journal of Pragmatics 55: 140-161.

Conboy, Martin. 2014. Exploring the language of the popular in American and British newspapers 1833-1988: Introduction. Journal of Historical Pragmatics 15(2): 159-164.

Cordella, Marisa, Heather Large, and Veronica Pardo. 1995. Complimenting behavior in Australian English and Spanish speech. Multilingua 14(3): 235-252.

Grainger, Karen, Kerkam Z. Mansor, and Sara Mills. 2015. Offering and hospitality in Arabic and English. Journal of Politeness Research 11(1): 41-70.

Gu, Yueguo. 199o. Politeness phenomena in modern Chinese. Journal of Pragmatics 14: 237-57.

Herbert, Robert K., and Stephen Straight. 1989. Compliment-rejection versus compliment-avoidance: Listener-based versus speaker-based pragmatic strategies. Language and Communication 9(1): 35-47.

Hill, Beverly, Sachiko Ide, Shako Ikuta, Akiko Kawasaki, and Tsunao Ogino. 1986. Universals of linguistic politeness: quantitative evidence from Japanese and American English. Journal of Pragmatics 10(3): 347-371.

House, Juliane, and Gabriele Kasper. 1981. Politeness markers in English and German. In: Florian Coulmas (ed.), Conversational Routine. The Hague: Mouton, 157-186.

Kádár, Daniel. 2013. Relational Rituals and Communication: Ritual Interaction in Groups. Basingstoke, UK: Palgrave Macmilan.

Kádár, Daniel, and Juliane House. 2020a. Revisiting the duality of convention and ritual: A contrastive pragmatic inquiry. Poznan Studies in Contemporary Linguistics 56(1): 83-111.

Kádár, Daniel, and Juliane House. 202ob. The pragmatics of ritual: An introduction. Special issue of Pragmatics 30(1): 1-14.

Leech, Geoffrey N. 1983. Principles of Pragmatics. London: Longman. 
Pan, Yuling, and Daniel Kádár. 2011. Politeness in Historical and Contemporary Chinese. London: Continuum.

Ruhi, Sukriye, and Daniel Kádár. 2010. "Face" across historical cultures: A comparative study of Turkish and Chinese. Journal of Historical Pragmatics 12(1-2): 25-48.

Searle, John. 1969. Speech acts: An essay in the philosophy of language. Cambridge University Press.

Searle, John. 1975. Indirect speech acts. In: Peter Cole, and Jerry Morgan (eds.), Syntax and Semantics, Volume 3: Speech Acts. New York: Academic Press, 59-82.

Taboada, Maite. 2010. Discourse markers and coherence relations: Comparison across markers, languages and modalities. Linguistics and the Human Sciences 6(1-3): 17-41.

Tannen, Deborah. 1986. “That's Not What I Meant!” How Conversational Style Makes or Breaks Relationships. New York: Ballantine.

Waggoner, Kimberlee. 2016. What can state talk tell us about punitiveness? A comparison of responses to political mass shootings in the United States and Norway. Ph.D. dissertation. Old Dominion University. DoI: 10.25777/6e42-3262.

Zhu, Hua, Wei Li, and Yuan Qian. 20oo. The sequential organization of gift offering and acceptance in Chinese. Journal of Pragmatics 32: 81-103. 